\title{
A trajetória vocal de Milton Nascimento*
}

\section{THAIS DOS GUIMARÃES ALVIM NUNES ${ }^{* *}$}

\begin{abstract}
RESUMO: Com o intuito de contribuir para os estudos de canto popular no Brasil, este artigo apresenta um olhar panorâmico sobre o uso da voz pelo artista Milton Nascimento ao longo da carreira. Amparada pelas reflexões de Paul Zumthor acerca da performance, procurei descrever como Milton explora suas qualidades vocais e de que maneira vai incorporando novas formas de transmitir e emitir os textos e/ou sons que carrega em seu canto, a partir da escuta de sua obra registrada em disco. Além de dar foco a um dos grandes cantores da Música Popular Brasileira da segunda metade do século XX, acreditamos que, ao estimular a escuta atenta das formas de expressão vocal de cantores de referência, possamos colaborar para o campo de formação em canto popular.
\end{abstract}

PALAVRAS-CHAVE: Milton Nascimento. Canto popular. Voz cantada.

\section{The Vocal Trajectory of Milton Nascimento}

\begin{abstract}
This research looks at the recorded work of Milton Nascimento, who is considered one of the greatest Brazilian popular music singer. It shows a broad view of the use of his voice throughout his career. The goal is to contribute to the popular singing studies in Brazil. It focuses on describing how he explores his singing voice aided by Paul Zumthor's reflections on performance. It also points how he incorporates at new ways to convey and deliver the text and / or sounds. We hope to collaborate in the education of popular singing by stimulating attentive listening to the forms of musical expression of acknowledged singers of the second half of the $20^{\text {th }}$ century.
\end{abstract}

KEYWORDS: Milton Nascimento. Popular Singing. Singing Voice.

\footnotetext{
* Dada a natureza musical do presente artigo, este arquivo (em formato .pdf) é interativo e contêm áudios musicais. Ao longo do texto, se apresentam botões com o símbolo de play $(\boldsymbol{\nabla})$. Clicando neles, abrem-se caixas de diálogo que executam trechos de canções interpretadas por Milton Nascimento, colaborando para o entendimento do teor textual do artigo, bem como de seu objeto de estudo. Para um melhor desempenho, recomenda-se manipular o arquivo com exclusividade, ou seja, fechar navegadores de internet ou quaisquer outros programas que estejam em execução. As caixas de diálogo, uma vez abertas, devem ser fechadas (clicando no seu pequeno " $\mathrm{X}$ " que aparece no canto superior direito da caixa), para evitar que se sobreponham e sobrecarreguem o arquivo, comprometendo sua funcionalidade. Atenção: é necessário ter instalado o Adobe Flash Player em seu computador. Para atualizá-lo ou baixá-lo, acesse https://get.adobe.com/br/flashplayer/e siga as instruções.

** Thais dos Guimarães Alvim Nunes é professora da área de música do Departamento de Artes e Comunicação da UFSCar. É bacharel em Música Popular, mestre e doutora em Música pela Unicamp. Coordenadora do Programa de Extensão Música Popular: história, performance e ensino e responsável pelas disciplinas de Voz e Expressão e Canto Popular dos cursos de Licenciatura em Música nas modalidades presencial e a distância. E-mail: thaisdosgui@gmail.com
} 


\section{O século da (voz na) canção ${ }^{1}$}

e voltarmos o olhar para o século XX no Brasil, constatamos uma produção expressiva da canção popular que levou o compositor, pesquisador e
professor de linguística e semiótica, Luiz Tatit, a elaborar diversos trabalhos ${ }^{2}$ voltados à análise deste objeto, sobretudo na relação entre texto e melodia. Nas últimas décadas, a produção de pesquisas sobre a canção vem crescendo substancialmente nas áreas de história, sociologia, letras e música. Estudos sobre a performance da voz na canção, no entanto, ainda aparecem em menor quantidade.

Semelhante ao panorama diverso e vasto da canção popular produzida no Brasil no século XX, traçado por Luiz Tatit em um de seus livros, seria possível a elaboração de um trabalho que compreendesse a trajetória da voz na canção popular brasileira no século XX. A variedade de timbres, emissões, interpretações, personalidades e meios ${ }^{3}$ através dos quais estas vozes deram vida às canções levou tal produção ao (re)conhecimento mundial.

Para que a construção desta trajetória seja possível, pesquisas sobre os intérpretes e suas vozes, nas mais diferentes épocas, precisam ser realizadas, para subsidiar um olhar panorâmico do canto popular no decorrer de um século. Se observarmos um determinado período, identificamos características estéticas predominantes. Por outro lado, se acompanharmos a trajetória de um único cantor, é possível visualizar particularidades que se destacam das características predominantes de cada época. Com o intuito de contribuir para este campo de estudo, apresento, neste artigo, parte da minha pesquisa de doutorado, intitulada $A$ voz de Milton Nascimento em presença, em que mapeei um conjunto de características vocais e interpretativas do artista no decorrer de sua carreira.

\footnotetext{
1 Referência ao livro O século da canção, de Luiz Tatit (2008).

2 Para citar alguns: Musicando a Semiótica: ensaios (TATIT, 2011); Elos de Melodia e Letra (TATIT, 2008); O Século da Canção (TATIT, 2008); Todos Entoam: Ensaios, Conversas e Canções (TATIT, 2007); "Gabrielizar a vida" em Três Canções de Tom Jobim (NESTROVSKI, 2004); Análise semiótica através das letras (TATIT, 2001); O Cancionista: Composição de Canções no Brasil (TATIT, 1996); Semiótica da Canção: Melodia e Letra (TATIT, 1994).

${ }^{3}$ A rua, o teatro de revista, o rádio, o cinema, a televisão, os discos analógicos e digitais e a internet.
} 


\title{
Por uma escuta da voz na canção popular
}

\begin{abstract}
Com efeito, nas formas poéticas transmitidas pela voz (ainda que elas tenham sido previamente compostas por escrito), a autonomia relativa do texto, em relação à obra, diminui muito: podemos supor que, no extremo, o efeito textual desapareceria e que todo o lugar da obra se investiria dos elementos performanciais, não textuais, como a pessoa e o jogo do intérprete, o auditório, as circunstâncias, o ambiente cultural e, em profundidade, as relações intersubjetivas, as relações entre a representação e o vivido. De todos os componentes da obra, uma poética da escrita pode, em alguns casos, ser mais ou menos econômica; uma poética da voz não pode jamais (ZUMTHOR, 2007, p. 17-18, grifos do autor).
\end{abstract}

O trecho extraído das reflexões de Paul Zumthor está presente no prefácio do seu livro Performance, recepção e leitura, e compõe parte da resposta à quinta questão, fornecida a um questionário da revista italiana Linea d'Ombra, em 1986. A pergunta afirmativa assim se apresenta: "Sua orientação parece sobretudo antropológica". Estudioso da poesia oral e investigador das potencialidades da voz enquanto mediadora de conteúdos, Zumthor assegura, nesta questão, ser necessário adotar um ponto de vista antropológico da palavra humana em detrimento de dissertações sobre uma Escrita permanente, concreta e fundamental, presente nos últimos 20 anos (ZUMTHOR, 2007, p. 16). Considerar as várias faces para a observação da voz o faz destacar a diferença de autonomia entre texto e obra, esta última entendida como resultante das variáveis envolvidas na performance. Nesta direção, os textos de Paul Zumthor vêm fornecendo subsídios para a análise da canção popular. Para além da canção composta por texto, melodia e harmonia, sabemos que a sua existência plena se dá na execução do arranjo e na emissão do canto, conjuntamente reunidos na performance, onde qualidades materiais e simbólicas vão expressar, comunicar, ressignificar e dialogar. Zumthor se dedica, sobretudo, à observação multidimensional da voz, um instrumento a mais, presente na canção popular se comparada à música exclusivamente instrumental. A partir de sua "orientação antropológica", é possível ampliar a abordagem desta voz para os possíveis diálogos que o intérprete estabelece com o público, com o ambiente cultural, com diferentes atores que produziram num período anterior e/ou contemporâneo a ele. Conforme o trecho citado, no extremo, o efeito textual 
desapareceria, o que potencializa o alcance da voz performatizada. Sabemos que a voz pode emitir, ainda, sons desprovidos de conteúdos textuais, o que nos chama a atenção para sua capacidade de provocar uma percepção sensorial que levou Zumthor a preferir o termo vocalidade à oralidade (ZUMTHOR, 1993). Para além de um modo oral de transmissão intermediado pela voz e pelo ouvido há, nesta voz que transmite, valores a ela agregados.

\section{A escolha de Milton Nascimento}

A quase totalidade das pesquisas ${ }^{4}$ e artigos acadêmicos, livros e sites que traz Milton Nascimento como parte do tema ou tema principal ressalta suas competências vocais, composicionais e interpretativas. Há múltiplas abordagens possíveis na obra deste artista, que realiza diferentes batidas e progressões de acordes não convencionais no violão, improvisa melodias e contracantos dissonantes, emprega formas musicais irregulares, utiliza fórmulas de compassos ímpares, emprega polirritmias, mistura harmonias tonais com modais, compõe e interpreta música instrumental com a voz. Para além de esgotar as possíveis linhas de investigações da sua obra, lanço um olhar sobre as maneiras com que Milton explora sua voz ${ }^{5}$ ao longo da carreira.

\footnotetext{
${ }^{4}$ Aqui me refiro, principalmente, às pesquisas acadêmicas sobre o Clube da Esquina, que aparecem listadas na bibliografia ao final.

${ }^{5}$ A produção de Milton Nascimento me acompanha desde o período de graduação. Ao desenvolver uma Iniciação Científica sobre Lô Borges (NUNES, 2000), ouvi muitos discos do artista, o que me levou a pesquisar o Clube da Esquina no mestrado (NUNES, 2005). A pesquisa teve enfoque maior nos aspectos composicionais, mas revelou a necessidade de uma abordagem futura sobre a voz de Milton Nascimento. Ao longo da minha pesquisa de doutorado (NUNES, 2015), encontrei apenas dois trabalhos com foco exclusivo na voz de Milton Nascimento: $O$ uso da voz como instrumento por Milton Nascimento na década de 70, pesquisa de Iniciação Científica desenvolvida por Luísa Nemésio Toller Motta junto ao Instituto de Artes da Unicamp (2010), que expõe a análise da gravação de seis composições registradas em disco entre 1972 e 1978; e A voz como gesto, as tessituras do canto de Milton Nascimento, pesquisa de mestrado desenvolvida por Fabrícia do Valle Arcanjo junto ao Programa de Pós-Graduação em Estudos Literários da Universidade Federal de Juiz de Fora (2012), que se dedica à compreensão de uma mítica e uma mística da voz de Milton Nascimento. Ao rever a bibliografia para a escrita deste artigo, encontrei a pesquisa de doutorado de Mateus de Andrade Pacheco, defendida em 2014 junto ao Programa de Pós-Graduação em História da Universidade de Brasília, intitulada Milton Nascimento: num canto do mundo, o conto do Brasil. Em outras pesquisas que abordam o canto, a voz de Milton Nascimento é trazida conjuntamente à análise de outros cantores como, por exemplo, em Da intenção ao gesto interpretativo: análise semiótica do canto popular brasileiro, pesquisa de doutorado de Regina Machado desenvolvida junto à área de Semiótica e Linguística Geral da Faculdade de
} 
Mesmo inserido numa lógica de mercado da produção cancional, Milton atesta a força expressiva da voz humana, capaz de superar padrões e extrapolar fronteiras ao exprimir desde os sons mais orgânicos (gemidos, sussurros, gritos etc.), passando pela fala e o canto em sua plenitude, indo do grave masculino ao agudo feminino, com ou sem palavras. Seus contrapontos vocais não obedecem às regras de escrita tradicional de escola; seus desenhos melódicos improvisados e dissonantes aproximam-se mais da música de comunidades tradicionais do que do jazz; a sobreposição de vozes em uníssono ou em oitavas em defasagem sugere um ambiente coletivo de vozes em eco, por serem emitidas pelo próprio cantor, numa conexão com o mito e a magia, e diferencia-se da maneira com que a música coral explora tais recursos, cuja sincronia é condição obrigatória. Ao longo da carreira, além de solista, o canto aparece em duas, três ou mais vozes, sobrepondo a própria voz ou combinando-a com cantores, compositores, crianças, instrumentistas ou pessoas comuns. Diferentes timbres são reunidos de maneira a preservar a unicidade de cada voz dentro do coletivo: uma atitude diferente daquela tomada pela música coral, erudita ou popular, ou mesmo pelos grupos vocais, nos quais a timbragem das vozes, para que soem homogêneas, é uma prática sobre a qual muitos grupos dedicam grande parte de seus ensaios. Ainda que vivendo em uma sociedade moderna, Milton revela, por meio de sua música, uma proximidade com o modo de criar de sociedades mais tradicionais, frequentemente mediado pela voz. Do ponto de vista técnico-interpretativo, encontramos aproximações na exploração timbrística (uso de diferentes cores na extensão vocal, voz soando como outro instrumento ou gerando novos timbres ao dobrar a linha melódica de outro instrumento), além das expressões de fala, gritos, sussurros, registrados em alguns discos de sua carreira, numa proximidade com um ambiente ritual. Este modo de fazer, que encontra ecos na oralidade por valorizar a presença "física" nas trocas culturais e nos processos de criação e gravação dentro e fora do Brasil, permite a Milton agregar expressões musicais a sua maneira, e se transforma numa variável que dá destaque ao seu trabalho.

Filosofia, Letras e Ciências Humanas da Universidade de São Paulo (2012) e em O canto popular brasileiro: análise acústica e interpretativa, dissertação de mestrado de Adriana Noronha Piccolo desenvolvida junto à Escola de Música da Universidade Federal do Rio de Janeiro (2006). 
Todas estas constatações, no entanto, só fazem sentido quando podemos percebê-las auditivamente. Com o privilégio de termos a totalidade de sua obra gravada, a grandiosidade da voz e das interpretações de Milton Nascimento pode ser ouvida panoramicamente por meio de pequenos trechos editados, de um conjunto de gravações registradas em disco ao longo da carreira, os quais apresento a seguir. Importante mencionar que nada substitui a audição completa das gravações, que pode - e deve - ser feita num tempo mais expandido do que é possível aqui tratar.

\section{A trajetória vocal}

A obra de Milton Nascimento, gravada de 1964 a 2015, está registrada em 40 discos, ${ }^{6}$ somando $527^{7}$ gravações entre composições instrumentais e canções, sendo estas últimas predominantes. Desde o início da carreira, Milton estabeleceu diálogos musicais dentro e fora do Brasil. Tanto que seu segundo LP, de 1969, intitulado Courage, foi gravado no exterior ${ }^{8}$ com a participação do pianista de jazz Herbie Hancock, arranjos de Eumir Deodato e com o experiente produtor Creed Taylor, ${ }^{9}$ responsável pela produção anterior de outros artistas brasileiros como Tom Jobim e João Gilberto: uma realização pouco comum aos artistas iniciantes até então. Demonstrando habilidade para agregar sonoridades, além de criatividade para mesclar, transformar e fazer surgir novas combinações melódicas e harmônicas, Milton vai desvelando, ao longo da carreira, sua expressão musical e vocal,

6 Conforme considerado no site oficial do artista (disponível em <http://www.miltonnascimento.com.br/>, acessado em 7 jun. 2016.) Não incluímos aqui a remasterização do disco Travessia, de 1967, lançado em CD em 2002, a coletânea Milton Nascimento Uma travessia Musical, de 1999, nem seus registros em DVDs (5), suas trilhas para longas-metragens (13) e suas participações em projetos específicos e discos de outros compositores.

7 Aproveito para indicar que, em minha tese, não considerei o primeiro disco, Barulho de Trem, gravado com o conjunto Holiday em 1964, antes de Milton ser conhecido como Milton Nascimento, uma vez que não tive acesso às gravações, nem o último, lançado em 2015 após a entrega do texto final da tese, intitulado Tamarear, gravado com Dudu Lima trio, totalizando naquela ocasião 38 discos, como descrito. A soma de composições que considerei no montante destes 38 discos foi de 326, uma vez que estava mencionando o número de composições diferentes, já que me dediquei a listar as 74 composições regravadas em diferentes discos no decorrer da carreira. Neste artigo, o número 527 diz respeito ao número de gravações, incluindo os dois discos mencionados e as reinterpretações.

${ }^{8}$ A primeira, de outras experiências estrangeiras, como Native Dancer (1975); Milton (1976) e Journey to down (1979).

9 Dicionário Cravo Albin da Música Popular Brasileira, versão online. Disponível em: <http://www.dicionariompb.com.br/creed-taylor/biografia>. Acesso em: 11 set. 2014. 
resultante do trabalho coletivo com músicos e compositores predominantemente mineiros, outros originários do estado do Rio de Janeiro, além dos encontros musicais vivenciados com diferentes artistas. ${ }^{10}$

\section{Há canções e há momentos - primeira fase ${ }^{11}$}

Ao percorrer a trajetória vocal de Milton Nascimento, é possível identificar três fases mais ou menos distintas. A primeira delas está localizada no início da carreira (1967-1969); a segunda, na década de 1970 (1970-1979); e a terceira, nos anos de 1980 e 1990. Ao ouvir cada um dos discos na sua totalidade, (Travessia, 1967; Courage, 1969; Milton Nascimento, 1969), percebemos que, na primeira fase, Milton surge enquanto um cantor que explora o registro modal nas três regiões (grave, média e aguda), já com ampla tessitura e sonoridade mais homogênea e contida Ocorre maior projeção em regiões agudas de algumas canções, em decorrência do desenho melódico da própria composição ("Travessia”, 1967 ,12 1969; "Canção do Sal", $1967-$ ). A emissão se apresenta mais coberta, resultando num som arredondado. Com timbre rico em harmônicos graves e ampla ressonância nas variadas regiões exploradas, a voz é utilizada para expor a melodia das composições que, nesta fase, trazem predominantemente uma textura de melodia acompanhada. Encontramos algumas exceções, como na composição “Catavento” (1967) - , na qual

\footnotetext{
${ }^{10}$ Há um conjunto de pesquisas acadêmicas sobre o Clube da Esquina que explicitam os compositores, parceiros e músicos com os quais Milton trabalhou entre 1967 e 1980. O site do Museu do Clube da Esquina (disponível em <http://www.museuclubedaesquina.org.br/>) também retoma, desde os anos 60 até a atualidade, trajetórias de artistas que trabalharam com os precursores do Clube da Esquina. Maria Dolores Pires do Rio Duarte descreve a trajetória artística de Milton, em seu livro intitulado Travessia: a vida de Milton Nascimento, relatando com detalhes os encontros que se deram com diversos músicos ao longo da carreira. O livro de Chico Amaral, A música de Milton Nascimento, é outra fonte de informação sobre com quem Milton tocou e gravou, a partir de entrevistas descontraídas realizadas com o artista.

${ }^{11}$ Este e os próximos subtítulos deste artigo são trechos da canção "Canções e Momentos", de Milton Nascimento e Fernando Brant, gravada no disco Yauretê, de 1987: Há canções e há momentos/eu não sei como explicar/em que a voz é um instrumento/que eu não posso controlar/Ela vai ao infinito/ela amarra todos nós/e é um só sentimento na plateia e na voz/Há canções e há momentos/em que a voz vem da raiz/e eu não sei se é quando triste/ou se quando sou feliz/Eu só sei que há momento/que se casa com canção/de fazer tal casamento/vive a minha profissão. A escolha de tais trechos deu-se por acreditarmos que eles sintetizam a trajetória vocal do artista estudado.

${ }^{12} \mathrm{O}$ ano ao lado das composições está relacionado ao ano do disco em que foram gravadas, uma vez que Milton constrói novas versões para muitas composições ao longo da carreira.
} 
Milton realiza a introdução, dobrando a linha melódica do contrabaixo com a voz, (em sílabas dom, tom, teim, dem) e, posteriormente, emite a melodia da composição instrumental juntamente com a flauta - Em "Gira, Girou" (1967) D, também podemos ouvir sua voz dobrar uma linha melódica do arranjo realizada pelo violoncelo (como em “Vera Cruz", 1969 - cantando a melodia principal em lá, lá, lá, e dobrando a melodia do arranjo no final em sílabas tom, dom - ). A presença de "Catavento" no primeiro disco da carreira já sinaliza a proximidade do artista com a música instrumental, que será potencializada ao longo dos anos. "Rio Vermelho" (1969) - um samba-jazz de forma irregular - na qual a voz aparece projetada e frontal em praticamente toda a gravação - é outro exemplo desta proximidade. A sonoridade jazzística marca o disco Courage (1969), com graves mais ressaltados no acompanhamento e improvisações mais livres, cuja estética ressoa na voz de Milton, conforme percebemos na escolha das sílabas para vocalizar a melodia na composição "Rio Vermelho": metade canção, metade instrumental (Ex. 1). Percebemos que, mais adiante na carreira, Milton vai privilegiar os sons vocálicos em contrapartida aos ataques consonantais em melodias vocalizadas.

\section{Ex. 1 Primeira exposição da parte A de "Rio Vermelho".}

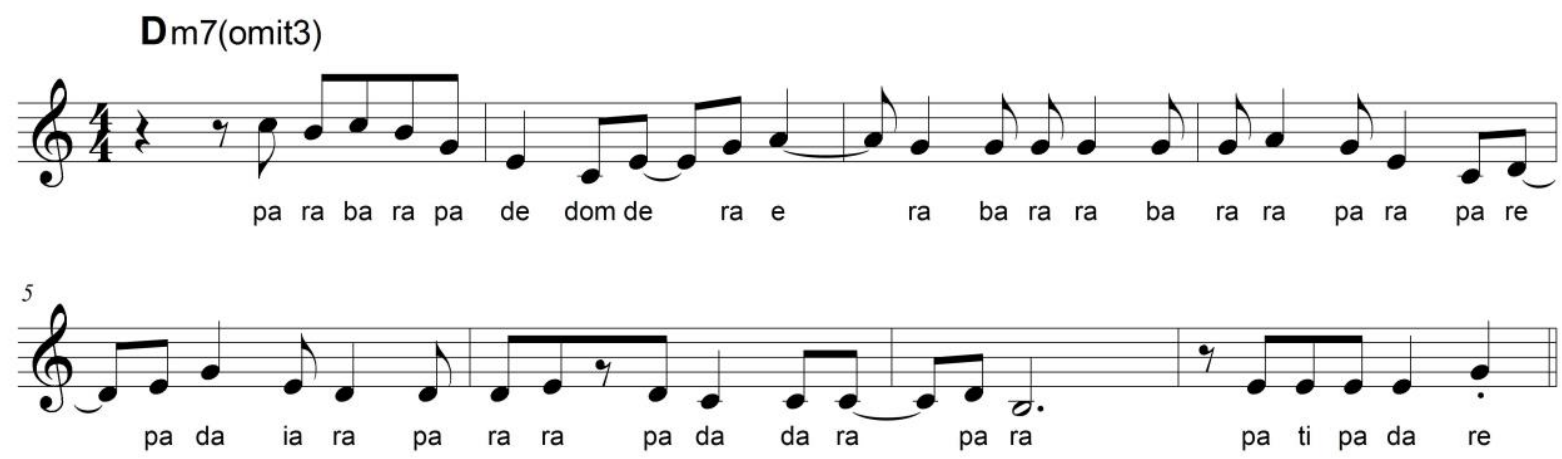

O lirismo e a adjacência com a estética vocal do samba-canção são revelados em “Maria, minha fé" (1967), por meio do uso do vibrato e prolongamentos vocálicos que ocorrem na região grave (e a vontade de se dar/ouço a tudo e meu silêncio/traz Maria junto a $\underline{\mathrm{mim}}$-). Por outro lado, o falsete é apresentado pela primeira vez, timidamente emitido nas notas mais agudas dos versos (meu trabalho, tudo feito pra Maria -). Ainda nesta canção - cuja melodia é 
predominantemente descendente -, Milton explora a voz contida em regiões agudas sobre um arranjo orquestral contrapontístico. Em “Outubro" (1967), notamos uma quebra na expectativa do ouvinte. Construída sobre uma forma pouco usual (ABCCA), a seção B soa como uma grande preparação para a seção $C$, realizando acordes maiores com sétima menor, e acordes maiores com quarta suspensa ${ }^{13}$ (com exceção do último acorde, que é resultante de empréstimo modal) dispostos de maneira ascendente (Asus $\rightarrow$ A7(13,9) $\rightarrow$ Csus $\rightarrow$ C7(9) $\rightarrow$ Dsus $\rightarrow$ D7(9) $\rightarrow$ Dsus $\rightarrow$ $\mathrm{Cm} / \mathrm{D})$. Este movimento ascendente - que desembocará num acorde de Sol maior com nona (G9) - também se manifesta na melodia e é seguido pelo acompanhamento e pela voz num crescendo de dinâmica. A expectativa é a de que se chegue à seção C (composta em tom maior, em contraste à seção $\mathrm{A}$, em tom menor) com voz projetada e potente. No entanto, o que ouvimos é uma voz contida e centralizada (Ah, jogar o meu braço no mundo), seguida por uma emissão mais metalizada (fazer meu outubro de homem), retornando, logo após, a uma posição mais central (matar com amor essa dor) - A falta de previsibilidade prende a atenção do ouvinte, que se surpreende ao ter sua expectativa interrompida. Já na gravação de "Outubro", do disco Courage, a voz chega projetada na seção $C$, mas ocorre um distanciamento do microfone no momento da gravação e a inserção de reverb, o que faz com que a voz se apresente num volume menor do que a seção anterior. Percebemos, ainda, que o andamento das canções fica mais acelerado nas regravações presentes no disco Courage (em “Travessia”, 1969; “Catavento”, 1969; e “Canção do Sal”, 1969, por exemplo).

Em "Sentinela" (1969) , podemos ouvir a clareza na pronúncia das sílabas, característica que irá acompanhar toda a carreira de Milton. O efeito reverb é inserido na vocalização - , trazendo profundidade e efeito de eco, e se compatibiliza com trechos da letra: "memória não morrerá/longe ouço esta voz/que o tempo não vai levar". Mais à frente, veremos tal efeito vincular-se não só à memória, mas também aos sonhos explorados nas letras do repertório gravado na década de 1970. Em “Rosa do ventre" (1969), identificamos o uso de ornamentação na melodia através da bordadura superior realizada rapidamente no trecho das frases: "velhas avenidas me cercando vou passar [ [...] corpo se descobre a outro corpo e nada mais" - A voz começa a

\footnotetext{
${ }^{13}$ Ver Amaral (2013, p. 366-367).
} 
aparecer mais mesclada à massa sonora do acompanhamento, como na introdução e no final da canção “Tarde” (1969) - Ainda nesta canção, a voz de Milton é contida, homogênea e pouco projetada , remetendo a uma emissão bossa-novista sobre um acompanhamento que se aproxima do samba-canção (samba lento em 2/4), além de trazer uma temática própria do gênero: “Das sombras quero voltar/somente aprendi muita dor/e vi com tristeza o amor/morrer devagar, se apagar...". Fica evidente que Milton traz no seu cantar e em parte de suas composições estéticas destes dois gêneros musicais.

No disco Milton Nascimento (1969), percebemos o uso privilegiado da percussão, que sai da posição de acompanhante para dividir o primeiro plano com a voz nas canções "Pescaria" - "Pai Grande" - "Quatro luas" - e "Aqui, ó" - Em "Aqui, ó", Milton mostra sua liberdade em transitar de uma articulação mais tematizada para outra mais distendida, ${ }^{14}$ como observado no trecho "tem benção de Deus/todo aquele que trabalha no escritório" $\longrightarrow$. Dentre as poucas aparições do falsete nesta primeira fase, podemos ouvi-lo em "Pai Grande" (1969), na entrada da seção B - Tal vocalização se dá com uso predominante de vogais (Ex. 2) e, mais uma vez, o reverb é utilizado, ambientando a voz no mesmo plano do acompanhamento.

Ex. 2 Vocalização em falsete na canção "Pai Grande". Gravação do disco Milton Nascimento (1969).

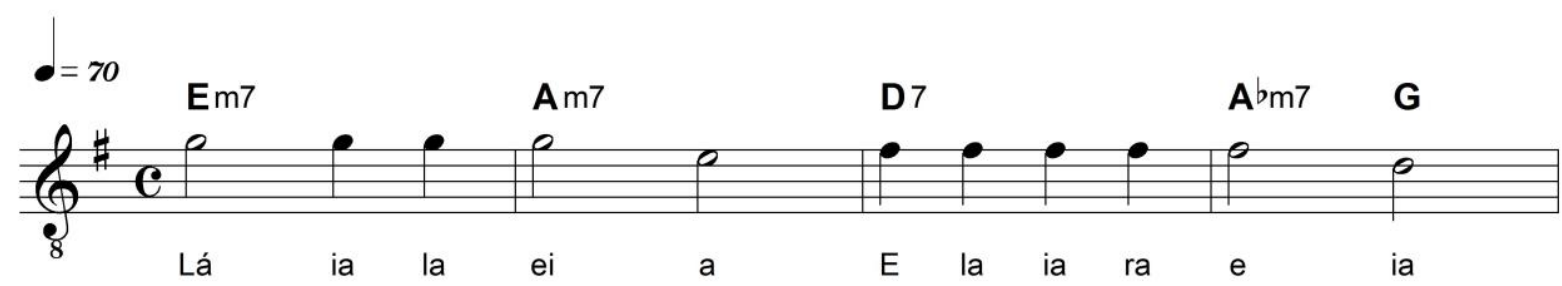

Milton inaugura o uso do falsete como um recurso timbrístico, que é emitido com leveza, tendo em vista que, no mesmo disco, podemos ouvir em "Sentinela" sua voz chegar a notas semelhantes, de maneira projetada e em registro modal (Ex. 3).

\footnotetext{
14 Tematização e Passionalização são termos utilizados na Semiótica da Canção, criada por Luiz Tatit, para tratar da relação texto/melodia, e são transpostos para a análise da voz por Machado (2012). No exemplo citado, a tematização na voz está relacionada à emissão mais precisa do ritmo, e a passionalização, ao alargamento do ritmo dentro dos compassos, que pode equivaler-se ao termo agógico em música, ou métrica derramada, utilizado por Ulhôa (1999).
} 


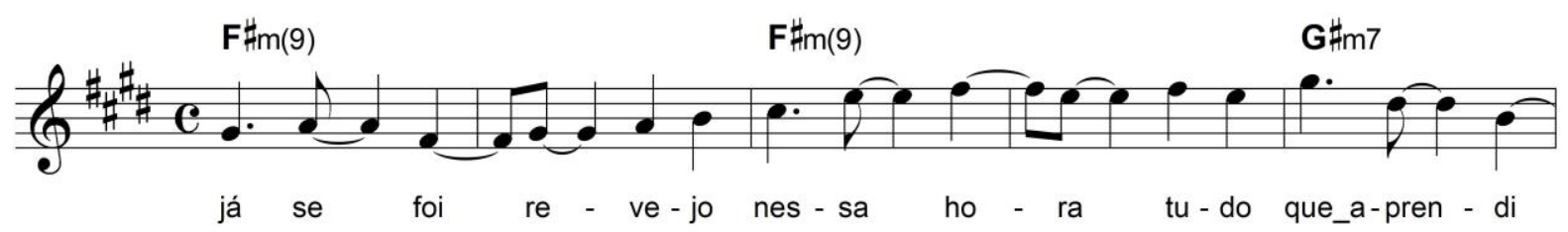

A primeira fase, marcada por uma entoação predominantemente cantada, já sinaliza a movência ${ }^{15}$ da voz, que veremos ser intensificada nos anos de 1970.

\section{A voz é um instrumento que eu não posso controlar - segunda}

\section{fase}

Acreditamos que o fato de Milton Nascimento transitar entre vários instrumentos (como a sanfona, o contrabaixo, o piano e o violão) tenha contribuído para a exploração timbrística e interpretativa da voz que notamos desde o início da carreira, e que este aspecto se intensifica na década de 1970. Além disto, o convívio com um grupo grande de músicos e compositores - incluindo os letristas, altamente competentes - cria uma ambiência que dá estímulo ao processo criativo e a experimentações. Aos poucos, fica claro que a variedade interpretativa do seu canto se harmoniza com a variedade das características intrínsecas da composição, tais como: as mudanças de andamento e/ou de rítmica ("Vera Cruz", 1969 ; "Três pontas", 1967 ; “Gira Girou", 1967 ; "Pescaria", 1969 ; "Beco do Mota", 1969 ; "Pai Grande", 1969 ; “Amigo, Amiga”, 1970 ; “Canto Latino", 1970 ; “Alunar", 1970 e “Os Escravos de Jó", 1973 são alguns exemplos); as misturas modal e tonal da harmonia, o uso concomitante de tonalidade maior e menor (“Crença”, 1967; “Tarde”, 1969; “Nuvem Cigana”, 1970; “Maria, Maria”, 1978); o uso

\footnotetext{
15 De acordo com Zumthor (1993, p. 145, grifo do autor), "movência é criação contínua". Ao contextualizar o termo na performance, o autor menciona: "A performance de uma obra poética encontra, assim, a plenitude de seu sentido na relação que a liga àquelas que a precederam e àquelas que as seguirão. Sua potência criadora resulta de fato, em parte, na movência da obra" (ZUMTHOR, 1997, p. 265 , grifo nosso). A "potência criadora" da voz de Milton pode ser observada nas reinterpretações de variadas composições retomadas ao longo da carreira. O exemplo mais ressaltado é o da canção "Clube da Esquina № 2", analisada detalhadamente na minha tese.
} 
de acorde de dominante menor ("Travessia"); os compassos ímpares ("Rosa do Ventre", 1969 com mudança de fórmula de compasso de 7/4 para 2/4; "Saídas e Bandeiras", 1972 ; "Cravo e canela", 1972 - ; "Lilia”, 1972 ); a junção de estilos variados de ritmos num mesmo disco (Milton, 1975); ou ainda a imprevisibilidade de repertório (presença da canção “Felicidade", de Tom Jobim, no disco Milton, 1970, gravado com a banda Som Imaginário,por exemplo); as polirritmias ("Sentinela", 1969 ; "Pai Grande", 1969 ; "Sunset Marquis 333 Los Angeles", 1969 ). São estas algumas das variáveis. Já no período anterior (1967-1969), notamos que praticamente toda a estrutura formal do arranjo já está definida na própria composição.

O período que estamos considerando como segunda fase, do ponto de vista vocal, abarca um conjunto de dez discos: Milton (1970); Clube da esquina (1972); Milagre dos peixes (1973); Milagre dos peixes ao vivo (1974); Minas (1975); Native dancer (1975); Geraes (1976); Milton (1976); Clube da esquina 2 (1978) e Journal to down (1979). Escolhemos destacar características vocais que não se manifestaram - ou que apareceram de maneira tímida - nos discos anteriores.

Em Milton (1970), por exemplo, pela primeira vez ouvimos um som vocal ruidoso, utilizado como recurso interpretativo, que parece misturar o registro basal ${ }^{16}$ com o modal na canção "Amigo, amiga", no trecho "/em terras de beira-mar/" Milton faz uso localizado de entoação próxima àfala no final do verso "/ meu coração é deserto/" (o que ocorrerátambémem "Ao que vai nascer" (1972), na frase "/respostas virão do tempo/" - e no trecho "/ um espelho feria meu olho/[...] vinhos do $\underline{s u l}$ ) . As ornamentações da melodia começam a ganhar mais espaço. Ouvimos em "Amigo, amiga" (1970) a inserção de bordadura em nota sustentada (/o rumo de encontrar/) $>$ e a inserção de notas de passagem cromáticas como mostrado no trecho a seguir (Ex. 4):

\footnotetext{
${ }^{16} \mathrm{O}$ registro basal ou fry permite alcançar notas extremamente graves. "Em virtude de um índice de crepitação percebido auditivamente na produção deste tipo de som, ele também recebeu o nome de fry (frito)" (MACHADO, 2012, p. 50).
} 
Ex. 4 Exemplos de ornamentação da melodia em "Amigo, amiga" (1970)

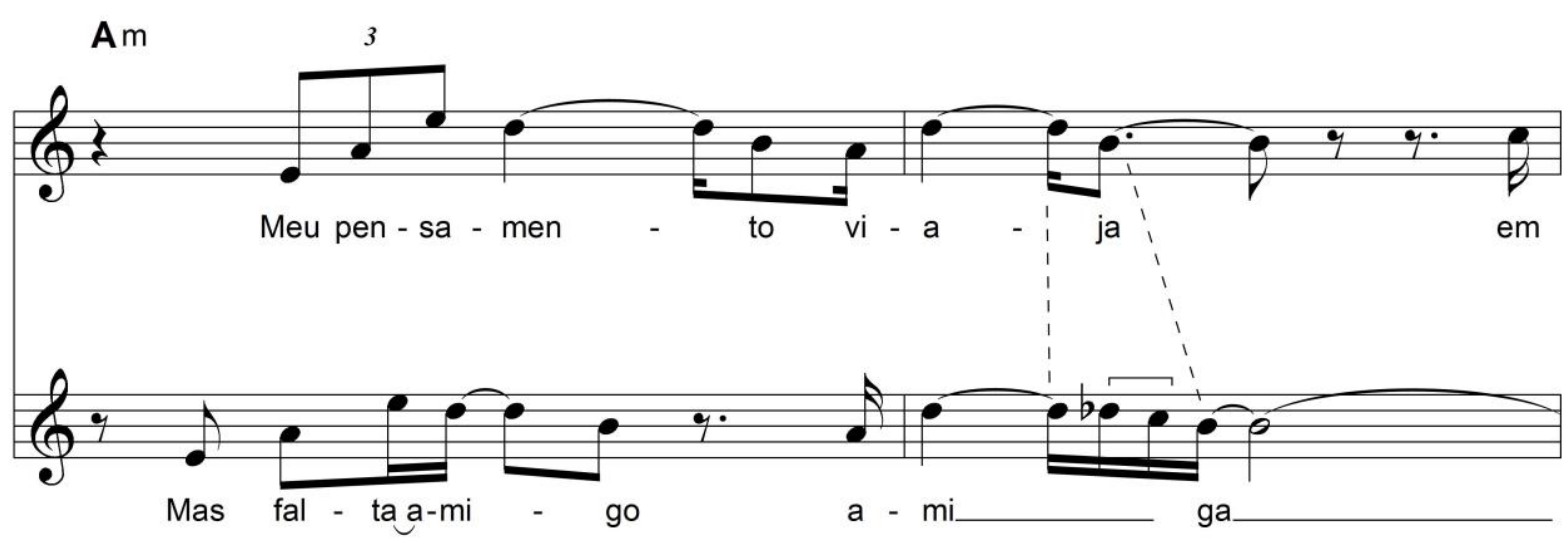

Há projeção frontal com impulso sonoro vigoroso em "Maria, três filhos" (1970) - Em “Durango Kid" (1970), ouvimos portamentos descendentes, os quais Milton utilizará com frequência ao longo da carreira (de terça maior para fundamental do acorde, por graus conjuntos no trecho "/Durango Kid/" - e de quinta para quarta do acorde em "/ eu vim trazer/"

Apresentar a melodia da canção com a voz dobrada por um instrumento é outra característica que se tornará recorrente, como já havia ocorrido em "Catavento", 1967 (voz e flauta); e agora em “Clube da Esquina”, 1970 (voz e violão) ; “Nuvem Cigana”, 1972 (voz e guitarra) ; “Clube da Esquina no 2", 1972 (voz e violão) $\downarrow$, e muitas outras canções. Tal dobra é utilizada, ainda, na construção de contracantos e improvisos como ocorre em "Dos Cruces" (1972) - "Clube da Esquina no 2" (1972) - "Me deixa em paz" (1972) > e "Ao que vai nascer" (1972)

Percebemos que, a partir do disco Clube da Esquina (1972), Milton manipula com mais domínio a região aguda do registro modal de maneira a suavizar a passagem da voz de cabeça para o falsete. Para isso, ele emite com suavidade e em posição mediana tais notas agudas do registro modal, o que pode ser observado nas canções "San Vicente" —, "Clube da Esquina no 2" procedimento permite agregar mais uma maneira de se chegar a regiões agudas. Notamos que a emissão vai se tornando mais clara do que no início da carreira, e o vibrato é utilizado de maneira econômica. O caráter imprevisível da interpretação de Milton se mantém. Ainda no disco Clube da Esquina (1972), por exemplo, ouvimos sua 
voz alcançar agudos de maneira mais homogênea e suavizada, como mencionado anteriormente, ou projetada frontalmente com alta pressão subglótica em "Os povos" $\checkmark$, ou, ainda, projetada inteiramente em falsete como em "Lilia"

No disco Milagre dos Peixes (1973), a voz é predominantemente ambientada no interior da massa sonora dos instrumentos, cuja profundidade é ressaltada com o uso do reverb. Milton mostra o poder de alcance de sua voz ao atingir notas

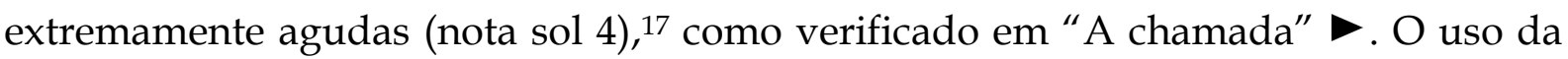
respiração como recurso expressivo pode ser verificado em "Sacramento"

Milagres dos peixes ao vivo (1974) inaugura o primeiro do amplo conjunto de discos ao vivo gravados por Milton Nascimento ao longo da carreira. Naturalmente, a voz é tomada pela carga emotiva de uma apresentação ao vivo e, principalmente, pelo fato de o disco se remeter ao trabalho anterior (que teve um grande número de canções censuradas). Milton alterna entoação de fala e canto nas canções "Outubro" e "Sabe Você" Assim como em muitos de seus discos ao vivo, canções inéditas são apresentadas; no caso deste, a canção "Viola, Violar" - Ouvimos ainda Milton reproduzir o efeito de eco com voz, ao repetir palavras do texto da canção, dando a elas mais de um sentido, como na canção "Bodas" (Chegou no porto um canhão/dentro de uma canhoneira, neira, neira.../com o cacau dessa mata, mata, mata...) D. Aqui a palavra "mata" se refere tanto à natureza quanto ao verbo matar. Presente na versão ao vivo de um disco de estúdio que teve grande parte das canções censuradas, certamente faz com que o canto potencialize o sentido da letra. Tal prática se repetirá vinculada à estrutura da própria composição, como em "Clube da Esquina no 2" (1993), por exemplo: "/Nem lembra se olhou pra trás/ ao primeiro passo, aço, aço, aço.../" $>$.

Os anos de 1975 e 1976 são marcados por quatro produções em disco, extremamente refinadas do ponto de vista composicional e interpretativo: Minas (1975), Native Dancer (1975), Geraes (1976) e Milton (1976). Enquanto intérprete, Milton confirma sua competência e criatividade para interpretar vocalmente diferentes ritmos, em andamentos variados, com linhas melódicas contendo diferentes níveis de

\footnotetext{
${ }^{17}$ Estamos seguindo o padrão de numeração que considera o dó central como 3.
} 
dissonância e complexidade, a uma ou mais vozes, e utilizando variadas cores timbrísticas, emissões e maneiras de entoar sua voz.

No disco Minas (1975), as vozes de criança aparecem agora diluídas ao longo do disco e em coro. "Trastevere" é a canção do disco que apresenta as características mais diferentes do que já vinha sendo apresentado nos trabalhos anteriores, e se desenvolve por meio de uma fala cantada $\rightarrow$. Notamos o uso mais ressaltado de vibrato na emissão, conferindo maior corpo ao timbre. Em Native Dancer (1975), as canções regravadas são interpretadas em andamento acelerado. O falsete é utilizado em grande quantidade nas melodias principais, nos contracantos e em diálogo com o saxofone de Wayne Shorter. Na composição "From the Lonely Afternoons", inclusive, Milton aproxima o timbre de sua voz ao do saxofone do jazzista Em Geraes (1976), há emprego ressaltado do coro formado pelos músicos participantes. O disco traz o encontro harmonioso das vozes de Milton e Mercedes Sosa. Com passagem homogênea da voz de cabeça para a voz de peito, Milton promove uma timbragem equilibrada com a voz da cantora na canção "Volver a Los 17" Em "Menino", a voz está a serviço do texto, cujo grito é expresso através da voz projetada frontalmente no agudo - . No dueto que realiza com Chico Buarque em “O que será (à flor da pele)", mais uma vez as vozes se equilibram. No momento em que há abertura de vozes, Milton realiza a melodia de forma mais aguda, enquanto que Chico fica na região mais grave, fator que compensa a natureza da voz do compositor, aguda e nasal, em comparação à de Milton Nascimento, rica em harmônicos graves . "Carro de Boi" traz glissandos de maneira ressaltada, além de apresentar a voz de Milton sobreposta em uníssono - (assim como em "Viver de amor" - ). Um novo recurso interpretativo que irá ocorrer em "Viver de amor", aliás, é o diálogo que Milton realiza entre sua voz em registro modal e em registro elevado - Emitindo timbres bem diferentes, tais sonoridades sugerem dois instrumentos, revelando "as vozes que ele [Milton] traz no interior"18 da própria voz. O mesmo ocorre em "Raça" - gravada no disco Milton (1976). Neste, a voz em presença ganha corpo sem texto nas composições "Francisco"

\footnotetext{
${ }^{18}$ Referência à letra da canção "A feminina voz do cantor", de Milton Nascimento e Fernando Brant. O trecho diz: "Quem entende essa voz sem as vozes que ele traz no interior?".
} 
Se comparado ao início da década de 1970, o timbre de Milton começa a trazer uma sonoridade mais metalizada no registro modal, e que pode ser verificada em “E daí?" - e "Testamento" - presentes em Clube da Esquina 2 (1978). Chama a atenção, no disco, um conjunto considerável de canções que começam em registro agudo ("Credo" - "Canção amiga" - , Mistérios" - , Dona Olímpia" - , "Tanto" - "Léo" —, "Meu Menino" — e "Que bom amigo" - ). "Canção da América" surge em Journal to Down (1979) $\downarrow$, em inglês e num estilo romântico, próximo a James Taylor. A maioria do repertório do disco é composta de regravações, com várias delas cantadas em inglês.

\section{A voz amarra todos nós}

A partir do disco Milton (1970), ouvimos a voz ser mais frequentemente agregada enquanto fonte sonora para a realização de contracantos, vocais, efeitos incidentais, além de ser usada como solista da melodia principal. Para isso, Milton agrega a voz do grupo que o acompanha, o que impacta na somatória de timbres, na variedade de linhas melódicas realizadas pela voz, ora dobrando-se umas às outras, ora se abrindo em duas ou mais vozes ("Maria, três filhos", 1970 ; "Clube da Esquina", 1970 ; “Durango Kid", 1970 ; "Pai Grande”, 1970 ; "Alunar”, 1970 ; "Dos Cruces", 1972 ; “Os Escravos de Jó", 1973 ; e "Saudade dos Aviões da Panair", 1975 , são alguns exemplos). No disco Clube da Esquina (1972), podemos ouvir os timbres de Milton e Beto Guedes mesclados em uníssono na melodia da canção "Saídas e Bandeiras no 1", sobre a qual ambos programam a mudança para o falsete na mesma região, mostrando consciência na construção interpretativa $\longrightarrow$. Tal mistura de vozes ocorre, também, entre Lô Borges e Milton nas canções "Cravo e canela" - "Pelo amor de Deus" - A inauguração da presença da voz infantil se dá no disco Milagre dos peixes (1973), com a canção "Pablo" - Os discos Minas (1975), Geraes (1976) e Clube da Esquina 2 (1978) trazem muitas canções com a participação vocal dos músicos envolvidos no projeto e de outros cantores. Além disso, são discos pensados enquanto unidade com presença de intervocalidades. As vozes infantis em coro surgem na introdução da primeira canção do disco Minas com 
nome homônimo "Minas" $\longrightarrow$, e emitem vocalizações da melodia da canção "Paula e

Bebeto" $\longrightarrow$, que aparecerá mais à frente no disco. As mesmas vozes voltam a aparecer no início de "Ponta de Areia", mas agora apresentando a melodia da própria canção. Os discos Minas e Geraes se conectam não apenas por sugerir conjuntamente o nome do estado brasileiro, mas pela emenda entre um e outro, através da execução do mesmo acorde no final da última canção de um (“Simples", 1975) - e primeira canção do outro ("Fazenda", 1976) $>$, dando a ideia de continuidade. Ambas as canções são do mesmo compositor, e suas temáticas as conectam. Além disto, o compositor da primeira canção de Minas ("Minas", 1975) é o mesmo da última canção de Geraes ("Minas Geraes", 1976), o que faz os dois discos serem pensados como um disco duplo, a exemplo de "Clube da Esquina" de 1972, e "Clube da Esquina 2", de 1978. Milton realiza, ainda, diálogos vocais com sua própria voz a partir do recurso de sobreposições, como podemos ouvir na canção “E daí?” (1978)

Já no disco Clube da Esquina 2 (1978) ouvimos, além das vozes dos instrumentistas, compositores e cantores convidados, a presença do grupo vocal Boca Livre na canção "Mistérios" que vem agregar à obra de Milton a sonoridade mais homogênea e timbrada característica de grupos vocais

\section{Um só sentimento na plateia e na voz - terceira fase}

Dos 17 discos gravados entre 1980 e 1999, sete são ao vivo. Dentre os registros ao vivo, alguns estão diretamente relacionados à produção anterior, como no caso do disco Os Tambores de Minas (1998), com seis novos registros para composições presentes no disco anterior, Nascimento (1997) (assim como em Milagre dos peixes ao vivo, de 1974, com seis composições presentes no disco homônimo de estúdio, gravado em 1973). Outros discos trazem um sentido celebrativo, como Corazón Americano (1984) - que registra o encontro entre Mercedes Sosa, Leon Gieco e Milton Nascimento, e inclui composições de outros artistas latino-americanos, como os argentinos Gustavo Santaolalla, Antônio Tarragó Ros, Ariel Petrocelli, Daniel Toro e Gustavo Santaolalla, a chilena Violeta Parra, o brasileiro Chico Buarque, os 
parceiros Ronaldo Bastos, Fernando Brant e Wagner Tiso, e ainda o cubano Silvio Rodriguez. A celebração ocorre, ainda, em A barca dos amantes (1986), que traz novos registros para cinco diferentes canções gravadas em momentos variados da carreira (“Tarde", 1969; “Nuvem Cigana”, 1972; "Maria, Maria”, 1978; “Louvação a Mariama”, 1982; “Lágrima do Sul”, 1985), com a participação do saxofonista Wayne Shorter, com quem Milton já havia dividido o disco Native Dancer (1975) e cuja sonoridade podemos ouvir no disco Milton (1976). O disco Amigo (1995), por sua vez, é uma produção que reúne a Orquestra Jazz Sinfônica, as vozes das crianças de dois corais (Crianças do programa Curumim e Rouxinóis, de Dinivópolis/SP), e traz os principais parceiros compositores (Fernando Brant e Márcio Borges), além de parcerias com Caetano Veloso e Chico Buarque. Dentre as 12 composições registradas, oito são novas interpretações para composições gravadas em diferentes momentos da carreira. O disco Milton Nascimento ao vivo (1983) apresenta, pela primeira vez, a famosa canção "Coração de estudante", que aparecerá novamente apenas em discos ao vivo, e as canções "Nos bailes da vida" (1981), "Um gosto de sol" (1972) e "Para Lennon e McCartney" (1970). Já O Planeta blue na estrada do sol (1991) celebra pessoas queridas, como Caetano Veloso, Chico Buarque, Edu Lobo/Chico Buarque, além de homenagear a Agostinho Santos com um de seus grandes sucessos ("Estrada do Sol”, de Tom Jobim e Vinícius de Moraes) e a John Lennon e Paul McCartney com a canção "Hello Goodbye". Num projeto mais específico, Missa dos quilombos (1982) surge para celebrar, nas palavras de Dom Pedro Casaldália, “a morte e a Ressurreição do Povo Negro, na Morte e Ressurreição do Cristo" ${ }^{19}$

O conjunto de discos de estúdio é formado por Sentinela (1980), Caçador de mim (1981), Anima (1982), Encontros e despedidas (1985), Yauaretê, (1987), Miltons (1988), Txai (1990), Angelus (1993), Nascimento (1997) e Crooner (1999). No disco Sentinela, ouvimos uma emissão mais frontal da voz de Milton. Ao coro, é dado outro caráter, com participação de grupos vocais autônomos, como Boca Livre (1980) e Roupa Nova (1981). Começamos a ouvir uma voz mais solista. Não há abandono dos contracantos vocais, mas uma redução no experimentalismo explorado na

\footnotetext{
${ }^{19}$ Trecho do encarte do disco Missa dos Quilombos (1982).
} 
década de 1970. No disco Caçador de mim (1981), os arranjos soam mais fechados e delimitados, com presença de convenções rítmicas trazendo a música pop. Milton começa a colecionar um conjunto de canções cuja interpretação arregimenta a grande massa ("Canção da América", 1980 ; "Caçador de mim", 1981 ; "Nos bailes da vida", 1981 ; “Certas Canções", 1982 ; “Coração de Estudante”, 1983 ; “Encontros e Despedidas", 1985 ). A voz continua a atestar a força expressiva de Milton, o instrumento diferenciado de grande poder sonoro, e sua flexibilidade em transitar por diferentes estéticas - como, por exemplo, suas vocalizações junto à orquestra em "Evocação das Montanhas" - do disco Anima (1982). Esta fase é marcada pelo uso recorrente das sobreposições de voz em uníssono ou em oitava. Milton canta em parceria com vozes consagradas da Música Popular Brasileira, como Nana Caymmi (1980), Caetano Veloso e Simone (1982), e Gal Costa (1983). Há a valorização das frequências agudas na equalização da voz nos discos. Inaugura-se o uso do falsete com sonoridade mais tensa, com emissão mais projetada, frontal e incisiva. O momento de maior demonstração deste falsete pode ser verificado em "Nuvem Cigana”, registrada no disco ao vivo A barca dos amantes (1986), nas repetições do trecho "/se você deixar o coração bater/" - Yauaretê (1987) traz a participação de Paul Simon, a canção “Morro velho", com levada pop, "Mountain” ("Irmão de fé") em castelhano, e "Canções e Momentos". O disco Txai (1990) é um projeto bastante específico, que resulta de uma viagem de Milton ao Acre. Milton reproduz parte da sonoridade dos índios com os quais teve contato. Angelus (1993) e Nascimento (1997) são outras duas grandes produções. Enquanto o primeiro traz um conjunto de grandes jazzistas - além de músicos e parceiros frequentes como uma grande reunião expandida para o mundo -, o segundo olha mais para o interior do artista, para os ritmos de Minas; apesar de, pela primeira vez, Milton cantar uma composição de Wayne Shorter, "Ana Maria”

Os discos lançados entre 2000 e 2015 celebrarão, predominantemente, o encontro de Milton com Gilberto Gil (Gil E Milton, 2000), com novas cantoras (Pietá, 2002), com os discípulos da bossa nova (Novas Bossas, 2008), com os irmãos franceses jazzistas (Milton Nascimento e Belmondo, 2009), com jovens aspirantes à carreira musical (... E a gente sonhando, 2010), além da comemoração dos 50 anos de carreira 
do cantor (Uma travessia, 2013), e por fim, um trabalho gravado conjuntamente com o Dudu Lima trio, um grupo mineiro de música instrumental brasileira, em homenagem aos 35 anos do projeto Tamar (Tamarear, 2015). Prestes a completar 74 anos, Milton continua se aventurando pelo falsete, criando novos improvisos e mantém vivo o "grão da (sua) voz". 20

\section{Considerações finais}

Percorrer a obra vocal de Milton Nascimento é deixar que o ouvido acompanhe os mais variados estímulos sonoros que emanam das "várias vozes que ele traz no interior". Percebemos que o artista vai construindo suas vocalidades ao longo da carreira, amparadas pelo diálogo que estabelece com suas próprias composições, no que diz respeito à variedade melódica, ao amplo preenchimento do campo da tessitura, aos diferentes caminhos harmônicos, aos ritmos diversificados e variantes. Milton cria por meio da voz, o que o impulsiona a cantar tanto melodias subjacentes quanto de superfície. As nuances timbrísticas que explora lhe dão liberdade para transitar, preencher, provocar e promover diálogo entre sua voz e ela mesma.

Mas a voz de Milton é endereçada ao outro, aos amigos, aos parceiros, aos músicos. É nesta relação de parceria e cumplicidade que ele vai compondo timbres, ajustando emissões, construindo maneiras de dizer, realizando misturas, arriscando caminhos mais incomuns, incorporando gestos vocais e montando seus quadros de fotografias sonoros. Sua liberdade para explorar lhe permite encontrar novos caminhos para a voz, porque do risco ele descobre o diferente. Milton é saudosista sem deixar de ser transgressor. Sempre que música e letra lhe são favoráveis, ele se conecta às vozes do passado e localiza suas referências.

Suas memórias transitam através de suas intervocalidades. O improviso de “Clube da Esquina no 2", presente no disco Angelus (1993), surge em 1972 e transita pelas canções “Dos Cruces" (1972), “Me deixa em paz" (1972), e “Ao que vai nascer" (1972). Tais notas, desenhando uma melodia de tons e semitons dissonantes,

\footnotetext{
${ }^{20}$ Referência ao conceito "grão da voz", de Barthes (2009).
} 
passeiam pelos "Povos", no disco Milton (1976). Nessas memórias, as melodias não são idênticas, mas a ideia se repete, se ressignifica e se conecta, assim como os passeios de "Ponta de areia" e "Paula e Bebeto" no interior dos discos; ou a retomada do amigo de "Morro Velho" em "Canção da América". As memórias são sonoras e escritas, naturalmente nômades.

A voz de Milton também se conecta ao público. Sua capacidade de síntese o leva a agregar diferentes culturas e estilos. Observar as nuances de seu canto é ampliar o conhecimento sobre as potencialidades expressivas que se materializam na sua voz em presença.

\section{Referências}

Artigo

ULHÔA, M. T. Métrica derramada: prosódia musical na canção brasileira popular. Brasiliana, v. 2, p. 48-56, 1999.

\section{Livros}

AMARAL, F. E. F. A música de Milton Nascimento. Belo Horizonte: Editora e Consultoria Gomes, 2013.

BARTHES, R. O grão da voz. In: O óbvio e o obtuso. Lisboa: Edições 70, 2009 [1972], p. 255-264.

DUARTE, M. D. P. do R. Travessia: a vida de Milton Nascimento. 4. ed. Rio de Janeiro: Record, 2011.

NESTROVSKI, Arthur. Três Canções de Tom Jobim . São Paulo: Cosac Naify, 2004, 93 p.

TATIT, Luiz. Musicando a Semiótica: ensaios. 2. ed. São Paulo: AnnaBlume, 2011, v. 1, $164 \mathrm{p}$.

. Elos de Melodia e Letra. 1. ed., São Paulo: Ateliê Editorial, 2008, 178 p.

. O Século da Canção. 2. ed., Cotia: Ateliê Editorial, 2008, v. 1, 251 p.

. Todos Entoam: Ensaios, Conversas e Canções. São Paulo: Publifolha, 2007, v. 1, $447 \mathrm{p}$.

. Análise semiótica através das letras. 1. ed., São Paulo: Ateliê Editorial, 2001, v. 1, $200 \mathrm{p}$. 
. O Cancionista: Composição de Canções no Brasil. São Paulo: EdUsp, 1996, 322 p.

. Semiótica da Canção: Melodia e Letra. 1. ed., São Paulo: Escuta, 1994, v. 1, 290 p.

ZUMTHOR, P. A letra e a voz: a "literatura" medieval. Tradução de Amálio Pinheiro e Jerusa Pires Ferreira. São Paulo: Companhia das Letras, 1993.

Introdução à poesia oral. Tradução de Jerusa Pires Ferreira, Maria Lúcia Diniz

Pochat e Maria Inês de Almeida. São Paulo: Hucitec, 1997.

Escritura e Nomadismo: entrevistas e ensaios. Tradução de Jerusa Pires Ferreira e Sonia Queiroz. Cotia: Ateliê Editorial, 2005.

. Performance, recepção e leitura. Tradução de Jerusa Pires Ferreira e Suely Fenerich. São Paulo: Cosac Naify, 2007.

\section{Iniciação Científica}

MOTTA, L. N. T. O uso da voz como instrumento por Milton Nascimento na década de 70. Relatório Final (Iniciação Científica). Campinas: IA-Unicamp, 2010.

NUNES, T. dos G. A. Buscando a essência da música de Lô Borges. Monografia (Iniciação Científica). Campinas: IA-Unicamp, 2000.

\section{Dissertações}

ARCANJO, F. do V. A voz como gesto, as tessituras do canto em Milton Nascimento. Dissertação (Mestrado em Letras: Estudos Literários). Juiz de Fora: Universidade Federal de Juiz de Fora, 2012.

PICCOLO, A. N. O canto popular brasileiro: uma análise acústica e interpretativa. Dissertação (Mestrado em Musicologia). Rio de Janeiro: UFRJ/EM, 2006.

\section{Teses}

MACHADO, R. Da intenção ao gesto interpretativo: análise semiótica do canto popular brasileiro. Tese (Doutorado). São Paulo: FFLCH-USP, 2012.

\section{Internet}

<http://www.miltonnascimento.com.br/>.

<http://www.dicionariompb.com.br/>. 


\section{Bibliografia}

\section{Produção acadêmica sobre o Clube da Esquina}

AMARAL, G. L.; ISIDORO, L. .; DELGADO, M.; OLIVEIRA, S. Clube da Esquina: a música como atrativo turístico. Monografia (Graduação em Turismo). Belo Horizonte: PUC/MG, 2004.

CANTON, C. A. P. "Nuvem no céu e raiz": romantismo revolucionário e mineiridade em Milton Nascimento e no Clube da Esquina (1970-1983). Dissertação (Mestrado em História). São João Del Rey: UFSJ, 2010.

CORRÊA, L. O. Clube da Esquina e Belo Horizonte: romantismo revolucionário numa cidade de formação ambígua. Dissertação (Mestrado em História). Belo Horizonte: PUC/MG, 2002.

DINIZ, S. C. "Nuvem cigana": a trajetória do Clube da Esquina no campo da MPB. Dissertação (Mestrado em Sociologia). Campinas: IFCH-Unicamp, 2012.

. Da Bossa Nova ao Clube da Esquina: diálogos e relações estético-musicais na música popular brasileira. Ouvirouver. Revista do programa de Pós-Graduação em Artes. Uberlândia: UFU, v. 11, n. 1, p. 218-236, jan./jun. 2015.

GARCIA, L. H. A. Coisas que ficaram muito tempo por dizer: o Clube da Esquina como formação cultural. Dissertação (Mestrado em História). Belo Horizonte: UFMG, 2000.

- Na esquina do mundo: trocas culturais na música popular brasileira através da obra do Clube da Esquina (1960-1980). Tese (Doutorado em História). Belo Horizonte: UFMG, 2006.

MARTINS, B. V. Som imaginário: a reinvenção da cidade nas canções do Clube da Esquina. Belo Horizonte: Editora UFMG, 2009.

NUNES, T. dos G. A. A sonoridade específica do Clube da Esquina. Dissertação (Mestrado). Campinas: IA-Unicamp: 2005.

NUNES, T. dos G. A. A voz de Milton Nascimento em presença. Tese (Doutorado). Campinas. IA-Unicamp, 2015.

OLIVEIRA, R. F. Mil tons de Minas: Milton Nascimento e o Clube da Esquina cultura, resistência e mineiridade na música popular brasileira. Dissertação (Mestrado em História). Uberlândia: UFU, 2006.

PACHECO, M. A. Milton Nascimento: Num canto do mundo, o conto do Brasil. Doutorado em HISTÓRIA. Brasília: UnB, 2014. 
QUEIROZ, M. P. Clube da Esquina: identidade, drible e diálogo. Monografia (Graduação em Jornalismo). Belo Horizonte: Centro Universitário Newton Paiva, 2004.

RODRIGUES, M. O modal na música de Milton Nascimento. Dissertação (Mestrado em Musicologia). Rio de Janeiro: Conservatório Brasileiro de Música do Rio de Janeiro, 2000 .

SBERNI JUNIOR, C. O álbum na indústria fonográfica: contracultura e o Clube da Esquina em 1972. Dissertação (Mestrado em História). Franca: Unesp, 2008.

SILVA, C. C. L. "De tudo se faz canção": sobre as escolhas temáticas na música do Clube da Esquina. Mestrado (Ciências Sociais). Rio de Janeiro: PUC/RJ, 2012.

SOUZA, A. C. Minas e Geraes: um recorte na cultura e na história através de Milton Nascimento. Dissertação (Mestrado em História). Niterói: Universidade Salgado de Oliveira, 2010.

STARLING, H. Coração americano: panfletos e canções do Clube da Esquina. In: REIS, D. A.; RIDENTI, M.; MOTTA, R. P. S. (Orgs.). O golpe e a ditadura militar: 40 anos depois (1964-2004). São Paulo: EDUSC, 2004.

TEDESCO, C. A. R. De Minas, mundo: a imagem poético-musical do Clube da Esquina. Dissertação de Mestrado em Multimeios. Campinas: Unicamp, 2000.

VIEIRA, F. C. S. F. Pelas esquinas dos anos 70: utopia e poesia no Clube da Esquina. Dissertação de mestrado em Poética. Rio de Janeiro: UFRJ, 1998.

VILELA, I. Nada ficou como antes. Revista USP, dossiê música brasileira, n. 87, São Paulo, USP, set./nov. 2010.

VITENTI, A. D. P. Uma certa musicalidade nas esquinas de Minas (1968-1978).

Dissertação (Mestrado em História). Brasília: UnB, 2010.

\section{Discografia de Milton Nascimento}

MILTON NASCIMENTO. Travessia. Rio de Janeiro: Dubas Música/Universal Music, 1967. (CD 325912004162).

. Courage. A \& M Records/PolyGram, 1969. (CD 393019-2).

. Milton Nascimento. Rio de Janeiro: EMI-Odeon, 1969. (CD 830432 2).

. Milton. Rio de Janeiro, EMI-Odeon, 1970. (CD 830433 2).

. Milagre dos peixes. Rio de Janeiro: EMI-Odeon, 1973. (CD 790790 2). 
. Milagre dos peixes ao vivo. Rio de Janeiro: EMI-Odeon, 1974. (CD 830430 2).

. Minas. Rio de Janeiro: EMI-Odeon, 1975. (CD 830431 2).

$611-2)$.

Milton (participação de Wayne Shorter). A\&M Records/PolyGram, 1976. (CD 394

. Geraes. Rio de Janeiro: EMI-Odeon, 1976. (CD 830428 2).

. Clube da Esquina 2. Rio de Janeiro: EMI-Odeon, 1978. (CD 791606 2).

. Journey to dawn. A\&M Records, 1979. CD.

. Sentinela. Ariola/PolyGram, 1980. (CD 813 357-2).

. Caçador de mim. Ariola/Polygram, 1981. (CD 837 258-2).

. Anima. Ariola/Polygram, 1982. (CD 813 296-2).

. Milton Nascimento ao vivo. Barclay, 1983. CD.

. Encontros e despedidas. Rio de Janeiro: Barclay/Polygram, 1985. (CD 827639

2).

. A barca dos amantes. Barclay/Polygram, 1986. (CD 831 349-2).

Yauaretê. CBS, 1987. CD.

. Miltons. CBS, 1988. (CD 231163).

Txai. CBS, 1990. CD.

. O planeta Blue na estrada do sol. CBS/Sony, 1991. CD.

. Angelus. Warner, 1993. (CD M945501-2).

. Amigo. WARNER, 1995. (CD 2 - 0825646519385).

. Nascimento. WARNER, 1997. (CD 3 - 0825646519385).

. Os tambores de Minas. WARNER, 1998. (CD 4 - 0825646519385).

. Crooner. WARNER, 1999.

. Gil E Milton. WARNER, 2000. 
Pietá. WARNER, 2002. (CD 1 - 0825646519385).

. Bossas Novas. EMI, 2008. (CD 212219 2).

. Milton Nascimento E Belmondo. Biscoito Fino, 2009. CD.

.... E a gente sonhando. EMI, 2010. (CD 946497 2).

. Uma travessia. Universal Music, 2013. (CD)

NASCIMENTO, Milton e BORGES, Lô. Clube da Esquina. Rio de Janeiro: EMI-Odeon, 1972. (CD 830429 2).

NASCIMENTO, M.; SOSA, M.; GIECO, L. LP Corazón Americano. Polygram, 1985.

NASCIMENTO, M.; CASALDÁliGA, P.; TIERRA, P. Missa dos Quilombos. Ariola, 1982. (CD 811 500-2).

SHORTER, W.; NASCIMENTO, M. Native Dancer. Nova Iorque: Columbia Records/Sony Music, 1975. (CD 49753). 